\title{
INTERFERENSI BAHASA BATAK MANDAILING DALAM TUTURAN BERBAHASA INDONESIA PADA ACARA PARPUNGUAN MASYARAKAT MANDAILING KOTA JAMBI
}

\author{
Afif Rofii ${ }^{1}$, Rizka Rani Hasibuan ${ }^{2}$ \\ Program Studi Pendidikan Bahasa dan Sastra Indonesia, \\ Fakultas Keguruan dan Ilmu Pendidikan, Universitas Batanghari, \\ Jambi \\ afif.rofii@unbari.ac.id \\ Rizkaranihasibuan17@yahoo.com
}

\begin{abstract}
This research is aimed at describing the types of Batak Mandailing language interference towards Indonesian language in the event Parpunguan masyarakat Mandailing Kota Jambi society. This research is qualitative descriptive. The data is taken from the utterances of Indonesian language which comprises Batak Mandailing language interference. The data is collected by using listening and tapping technique, observation, and speaking. The result of data analysis shows that there are grammatical interferences in the event parpunguan in Kota Jambi, namely; there are 8 utterances in the form of morpheme, there 6 utterances in the form of words, there are 28 utterances in the form phrase, there are 9 utterances in the form of clause, and there are 3 utterances in the form of sentence from those 54 data. The result of this research is being recommended to the expert of language, Badan Pembinaan dan Pengembangan Bahasa Provinsi Jambi, and head of custom to increase a kind of socialization in using Indonesian language to society correctly; Moreover, to the society who live in Kota Jambi especially Bataknese Mandailing to pay more attention to the use of Indonesian language correctly.
\end{abstract}

Keywords: Batak Mandailing Language Interference, Indonesian Language, Parpunguan

\footnotetext{
${ }^{1}$ Dosen Program Studi Pendidikan Bahasa dan Sastra Indonesia, Fakultas Keguruan dan Ilmu Pendidikan, Universitas Batanghari, Jambi

${ }^{2}$ Mahasiswa Program Studi Pendidikan Bahasa dan Sastra Indonesia, Fakultas Keguruan dan Ilmu Pendidikan, Universitas Batanghari, Jambi 


\section{PENDAHULUAN}

Manusia pada umumnya menggunakan bahasa dalam kehidupan sehari-hari, saat berbicara dengan seseorang atau melakukan aktivitas. Fungsi bahasa yang paling mendasar ialah sebagai alat komunikasi. Bahasa digunakan masyarakat sebagai alat pergaulan antarsesama dan alat untuk menyampaikan sebuah pemikiran. Menurut Chaer, dan Agustina, (2010:84) masyarakat Indonesia dapat menggunakan bahasa ibu (B1) dan mampu menggunakan bahasa Indonesia (B2) saat berkomunikasi. Setiap suku mempunyai bahasa daerah satu diataranya adalah bahasa Batak Mandaling.

Bahasa Batak Mandailing merupakan bahasa daerah masyarakat Tapanuli Selatan. Berdasarkan hasil wawancara penulis dengan penutur masyarakat Mandailing bermarga Nasution (Jumat, 17 November 2017) diketahui bahwa terdapat kekacauan bahasa yang dikalukan masyarakat dalam berbahasa Batak Mandailing yang tidak sesuai dengan kaidah dan aturan berbahasa. Contoh: Sada $\mathrm{Au}$ pada bahasa Batak Mandailing menyebutkan "satu aku", tetapi dalam bahasa Indonesia arti dari Sada Au adalah "sendiri”.

Sosiolinguistik adalah ilmu yang mempelajari bahasa dalam kaitannya dengan penggunaan bahasa dalam masyarakat. Pemakai bahasa seringkali menggunakan dua bahasa saat berkomunikasi, seperti pemakaian bahasa ibu (B1) serta pemakaian bahasa Indonesia (B2) saat berkomunikasi kepada orang lain (Rokhman, 2013:20). Berdasarkan hasil pengamatan penulis pada penutur masyarakat Mandailing pada acara Parpunguan di Kota Jambi (Jumat, 17 November 2017) diketaui bahwa terdapat interferensi bahasa Batak Mandailing ke dalam bahasa Indonesia. Interferensi tersebut, misalnya: Ke Kamian Atcogot Ustazah. Dalam bahasa Batak Mandailing yang sebenarnya Tu Hamian Atcogot Ustazah. Tu Hamian dalam bahasa Batak Mandailing artinya ke tempat/ ke rumah.

Interferensi merupakan kekacauan

bahasa dalam masyarakat yang disebabkan adanya unsur-unsur bahasa lain yang digunakan masyarakat bilingual dan multilingual (Weinreich dalam Chaer dan Agustina, 2010:120). Satu diantara bentuk interferensi yaitu masuknya serpihanserpihan bahasa Batak Mandailing ke dalam bahasa Indonesia saat berkomunikasi. Adapun interferensi yang sering terjadi meliputi jenis interferensi kultural, semantik, leksikal, fonologi, dan gramatikal (Ardiana (dalam Suandi, 2014: 119)). Pada penelitian ini, hanya dianalisis jenis interferensi gramatikal berupa morfem, kata, frasa, klausa, dan kalimat.

Berdasarkan latar belakang tersebut, maka fokus penelitian ini adalah analisis jenis interferensi bahasa Batak Mandailling dalam tuturan berbahasa Indonesia pada acara Parpunguan masyarakat Mandailing Kota Jambi?

Sesuai dengan tujuan penelitian ini untuk mendeskripsikan jenis interferensi gramatikal bahasa Batak Mandailing dalam tuturan berbahasa Indonesia pada Parpunguan masyarakat Mandailing Kota Jambi, penelitin ini juga juga berusaha menjawab pertanyaan bagaimana jenis interferensi gramatikal berupa morfem, kata, frasa, klausa, dan kalimat bahasa Batak Mandailing dalam tuturan berbahasa Indonesia pada acara Parpunguan masyarakat Mandailing Kota Jambi?

\section{Kajian Teoretis}

Bahasa pada umumnya digunakan masyarakat sebagai sarana dalam melakukan interaksi sosial. Menurut Dardjowidjojo (2005:16) "Bahasa adalah suatu sistem simbol lisan yang dipakai oleh anggota suatu masyarakat bahasa untuk berkomunikasi dan berinteraksi antarsesamanya, berlandaskan pada budaya yang mereka miliki bersama”. 
Dapat disimpulkan bahwa setiap daerah memiliki bahasa daerah masing-masing. Adapun kajian bahasa yang mempengaruhi bahasa dalam masyarakat ialah sosiolinguistik.

$\begin{array}{cccc} & \text { Menurut } & \text { Kridalaksana } & \text { (dalam } \\ \text { Chaer } & \text { dan } & \text { Agustina } & \text { 2010:3) }\end{array}$
sosiolinguistik lazim didefenisiskan sebagai ilmu yang mempelajari ciri dan pelbagai variasi bahasa, serta hubungan di antara bahasawan dengan ciri fungsi variasi bahasa itu dalam suatu masyarakat bahasa. Selanjutnya, Bram dan Dicky (dalam Rokhman, 2013:2) menyatakan sosiolinguistik mengkhususkan kajiannya pada bagaimana bahasa berfungsi di tengah masyarakat. Adanya bahasa daerah setiap suku memungkinkan terjadinya interferensi.

Menurut Alwasilah (dalam Aslinda dan Syafyahya, 2007:66) "Interferensi berarti adanya saling pengaruh antar bahasa”. Pengaruh itu dalam bentuk yang paling sederhana berupa pengambilan satu unsur dari satu bahasa dan digunakan dalam hubungannya dengan bahasa lain. Rumusan yang hampir sama dinyatakan oleh Lado dan Sunyono (dalam Aslinda dan Syafyahya, 2007: 66) pengaruh antar bahasa itu dapat juga berupa pengaruh kebiasaan dari bahasa pertama (ibu) yang sudah dikuasai penutur ke dalam bahasa kedua”. Dapat disimpulkan dari beberapa pendapat ahli di atas interferensi terjadi karena adanya penutur bilingualisme dan karena adanya penutur bilingualisme, dan multilingualisme yang memiliki kebiasaan menggunakan lebih dari satu bahasa saat berkomunikasi.

Pada umumnya, masalah kedwibahasaan (bilingualisme) timbul dari penutur yang menggunakan dua bahasa yang bebeda. Rofii (2016) mengatakan bahwa Bahasa pertama dapat mempengaruhi penggunaan bahasa kedua. Menurut Robert Lado (dalam Chaer dan Agustina 2010:86) "Bilingualisme adalah kemampuan menggunakan bahasa oleh seseorang dengan sama baiknya, yang secara teknis mengacu pada pengetahuan dua buah bahasa bagaimana pun tingkatnya”. Dapat disimpulkan bahwa bilingualisme merupakan kemampuan menggunakan dua bahasa yang sama baiknnya. Selain, penutur biligualisme interferensi juga terjadi karena adanya penutur multilingualisme. Menurut Mc Kay (dalam Lapasau dan Arifin, 2016:87) ada banyak faktor yang menjadi penyebab timbulnya masyarakat multibahasa yang mendukung teori multi bahasa, tetapi yang paling berpengaruh adalah migrasi.

Beberapa penelitian terdahulu yang mengkaji tentang interferensi yaitu: 1) penelitian yang dilakukan oleh Joko Sukoyo (2011), Universitas Negeri Semarang berjudul Interferensi Bahasa Indonesia dalam Acara Berita Berbahasa Jawa "Kuthane Dhewe" di TV Borobudur Semarang; 2) penelitian yang dilakukan oleh Anni Rahimah, Agustina, Syahrul R (2015), Universitas Negeri Padang berjudul Interferensi Bahasa Mandailing Dalam Bahasa Indonesia Tulis Siswa Kelas VIII MTS Baharuddin Kecamatan Angkola Kabupaten Tapanuli Selatan; 3) Sartini (2008), Universitas Batanghari dalam skripsinya yang berjudul Interferensi Penggunaan Tanda Tanya Bahasa Jawa terhadap Kalimat Tanya Bahasa Indonesia dalam Proses Belajar Mengajar Siswa Kelas II Jurusan Penjualan SMK Harapan Tahun Pelajaran 2007-2008; 4) Any Budiarti (2013), Universitas Pasundan Bandung dalam skirpsinya yang berjudul Interferensi Bahasa Indonesia Ke kalam Bahasa Inggris Pada Abstrak Jurnal Ilmiah.

\section{METODE PENELITIAN}

Jenis penelitian kualitatif
merupakan metode penelitian yang
dilakukan secara alamiah. Menurut
Muhammad $(2010: 23)$ "Salah satu
fenomena yang dapat menjadi objek
Berbahasa Indonesia pada Acara Parpunguan
ling Kota Jambi


penelitian kualitatif adalah peristiwa komunikasi atau berbahasa karena peristiwa ini melibatkan tuturan, makna semantik tutur, orang yang bertutur, maksud yang bertutur, situasi tutur, peristiwa tutur, tindak tutur, dan latar tuturan”. Dalam jenis penelitian kualitatif terdapat metode penilitian deskriptif. Menurut Sudaryanto (dalam Muhammad, 2011: 192) "Penelitian deskriptif yaitu penelitian yang dilakukan semat-mata hanya dilakukan berdasarkan pada faktafakta yang ada atau fenomena yang secara empiris hidup pada penuturnya sehingga yang dihasilkan atau yang dicatat berupa varian bahasa yang biasa dikatakan sifatnya seperti potret atau paparan seperti apa adanya”. Deskriptif ini sangat tepat untuk penulis jadikan sebagai jenis penelitian khusunya penelitian bersifat kualitatif.

Data yang dikumpulkan dalam penelitian ini, berupa ungkapan -ungkapan yang mengandung interferensi pada acara Parpunguan masyarakat Mandailing kota Jambi. Sumber data dalam penelitian ini adalah masyarakat penutur bahasa Batak Mandailing. Menurut Siswantoro (2010: 70) "Data primer adalah data utama, yaitu data yang diseleksi atau diperoleh langsung dari sumbernya tanpa perantara”. Data primer dalam penelitian ini diambil dari spercakapan yang berupa ungkapan dari informan yang berisi interferensi bahasa Batak Mandailing pada acara Parpunguan Masyarakat Mandailing Kota Jambi.

Menurut Muhammad (2011: 194) "Dalam sebuah penelitian, dapat ditetapkan tiga metode pengumpulan data, yakni (1) metode simak sadap; (2) metode observasi/pengamatan dan (3) metode cakap”. Langkah kerja dakam melakukan pengumpulan data dalam penelitian ini adalah sebagai berikut: a) teknik simak sadap, digunakan untuk memperoleh data mengenai interferensi bahasa Batak Mandailing; b) teknik pengamatan/observasi, digunakan untuk melakukan sebuah pengamatan terhadap objek penelitian yang akan diteliti; c) teknik cakap, digunakan untuk penyediaan data yang dilakukan dengan cara melakukan percakapan dengan penutur atau narasumber atau informan.

Adapun data dianalisis dengan serangkaian kegiatan analisis sebagai berikut: 1) memasukkan data yang terkumpul ke dalam tabel tabulasi data; 2) menganalisis data yang mengandung interferensi bahasa Batak Mandailng; 3) memeriksa dan menafsirkan data terklafikasi sebagai usaha menemukan jawaban tentang jenis interferensi bahasa Batak Mandailing; 4) mendeskripsikan data yang termasuk ke dalam jenis interferensi; 5) menyimpulkan hasil analisis data yang mengandung interferensi.

\section{HASIL DAN PEMBAHASAN}

Berdasarkan analisis data yang dilakukan, maka diperoleh hasil penelitian berupa jenis interferensi gramatikal bahasa Batak Mandailing terhadap bahasa Indonesia pada acara Parpunguan masyarakat Mandailing Kota Jambi. Jenis intereferensi gramatikal terdapat dalam 5 tataran yaitu: 1) morfem; 2) kata; 3) frasa; 4) klausa; dan 5) kalimat.

\section{Interferensi Berupa Morfem}

Pada acara Parpungan masyarakat Mandailing Kota Jambi, diketahui bahwa dari 54 tuturan secara keseluruhan terdapat bentuk tuturan berupa morfem sebanyak 8 tuturan. Adapun bentuk tuturan yang dimaksud dijelaskan sebagai berikut.

1) "Pertama-tama marilah kita mengucapkan puji syukur kepada Allah SWT berkat izinnya kita dilehen kesempatan sehingga bisa markumpul di bagas martua on

Artinya:Pertama-tama marilah kita mengucapkan puji syukur kepada 
Allah swt. berkat izinnya kita diberi kesempatan sehingga bisa berkumpul di rumah ketua ini.

Menurut Alwasilah (dalam Aslinda dan Syafyahya, 2007:66) "Interferensi berarti adanya saling pengaruh antar bahasa”. Adapun menurut Djajasudarma (2010:35) "Mofem adalah unsur bahasa yang memiliki makna dan ikut mendukung makna, yang melibatkan: unsur yang memliki makna (morfem bebas) dan unsur yang ikut mendukung makna (morfem terikat)". Jelas terlihat pada kata markumpul yang merupakan kosa kata bahasa Batak Mandailing yang bermakna "berkumpul" digunakan dalam konteks tuturan bahasa Indonesia. Dalam hal ini telah terjadi kekacauan pemakaian morfem terikat mar- menjadi ber-. Pembentukan kata markumpul terdiri atas morfem terikat mar- dan morfem bebas kumpul= markumpul, yang dalam bahasa Indonesia bermakna "berkumpul”, sedangkan dalam bahasa Indonesia kata berkumpul terdiri atas: morfem terikat ber- dan morfem bebas kumpul =berkumpul.

b) "Bahasa yang di pargunaon pertemuan keluarga ikanas orang kita Mandailing terpaksa bahasanya bercampur-campur”.

Artinya: Bahasa yang di pergunakan di dalam pertemuan ikanas orang kita mandailing terpaksa bahasanya bercampur-campur.

Menurut Alwasilah (dalam Aslinda dan Syafyahya, 2007:66) "Interferensi berarti adanya saling pengaruh antar bahasa”. Adapun menurut Djajasudarma (2010:35) "Mofem adalah unsur bahasa yang memiliki makna dan ikut mendukung makna, yang melibatkan: unsur yang memiliki makna (morfem bebas) dan unsur yang ikut mendukung makna (morfem terikat)”. Jelas terlihat pada kata bahasa Batak Mandailing pargunaon yang berarti “pergunakan” telah terjadi kekacauan pengunaan morfem terikat par-on menjadi per-kan. Kata pargunaon terdiri atas paron+guna = pargunaon yang berarti "pergunakan”, sedangkan dalam bahasa Indonesia pergunkana dibentuk oleh per$k a n+$ guna $=$ pergunakan .

\section{Interferensi Berupa Kata}

Interferensi gramatikal berupa kata berjumlah 6 tuturan, dari 54 tuturan keseluruhan. Interferensi tersebut diantaranya dijelaskan sebagai berikut.

a) Jadi informasi-informasi bisa ada parobahan". Artinya: Jadi, informasi yang didapat bisa terjadi perubahan.

Artinya: Jadi, informasi yang didapat bisa terjadi perubahan.

Pada tuturan tersebut, terdapat jenis interferensi berupa kata. Alwasilah (dalam Aslinda dan Syafyahya, 2007:66) menjelaskan bahwa "Interferensi berarti adanya saling pengaruh antar bahasa”. Selain itu, menurut Suhardi (2013:16) "Kata sebagai unsur sintaksis di dalam kalimat dapat menduduki fungsi sebagai subjek, predikat, objek, pelengkap, maupun menduduki fungsi sebagai keterangan”. Interferensi tersebut terjadi karena masuknya kata dari bahasa Batak Mandailing parobahan ke dalam tuturan berbahasa Indonesia. Parobahan tersebut bermakna "Perubahan".

b) Marsodakoh tidak harus hepeng apapun yang bermanfaat yang kita berikan itu sudah menjadi ibadah sodakoh”.

Artinya: Bersedekah tidak harus uang apapun yang bermanfaat yang kita berikan itu sudah menjadi ibadah sedekah.

Pada tuturan tersebut, terdapat jenis interferensi berupa kata. Alwasilah (dalam 
Aslinda dan Syafyahya, 2007:66) menjelaskan bahwa "Interferensi berarti adanya saling pengaruh antar bahasa". Selain itu, menurut Suhardi (2013:16) "Kata sebagai unsur sintaksis di dalam kalimat dapat menduduki fungsi sebagai subjek, predikat, objek, pelengkap, maupun menduduki fungsi sebagai keterangan". Interferensi tersebut terjadi karena masuknya kata dari bahasa Batak Mandailing ke dalam tuturan berbahasa Indonesia. marsodakoh tersebut dalam bahasa Indonesia bermakna“besedekah”.

\section{Interferensi Berupa Frasa}

Interferensi gramatikal berupa frasa berjumlah 28 tuturan, dari 54 tuturan keseluruhan. Interferensi tersebut diantaranya dijelaskan sebagai berikut.

a) “Cocok, kalau presiden nadong halak kita”

Artinya : Cocok kalau presiden, tidak ada orang kita.

Pada tuturan tersebut, terdapat jenis interferensi berupa frasa. Menurut Alwasilah (dalam Aslinda dan Syafyahya, 2007:66) "Interferensi berarti adanya saling pengaruh antar bahasa”. Selanjutnya, menurut Djajasudarma (2010:55) "Frasa adalah unsur sintaksis yang terkecil”. Interferensi tersebut terjadi karena masuknya frasa nadong halak dari bahasa Batak Mandailing ke dalam tuturan berbahasa Indonesia yang tidak sesuai dengan kaidah dan aturan bahasa yang benar. Frasa nadong halak tersebut dalam bahasa Indonesia bermakna"tidak ada orang”.

b) "Contohnya seperti almarhum saudara kita apa namanya itu indak tarida”.

Artinya: Contohnya seperti almarhum saudara kita apa namanya itu tidak

terlihat.

Interferensi Bahasa Batak Mandailing dalam Tuturan Berbahasa Indonesia pada Acara Parpunguan Masyarakat Mandailing Kota Jambi
Pada tuturan tersebut, terdapat jenis interferensi berupa frasa karena terjadi kekacauan penggunaan frasa bahasa Batak Mandailing dalam bahasa Indonesia yang tidak sesuai kaidah. Menurut Kridalaksana (dalam Sudipa, dkk, 2011:1) "Interferensi adalah kesalahan bahasa berupa unsur bahasa sendiri yang dibawa ke dalam dialek lain yang dipelajari”. Adapun menurut Djajasudarma (2010:55) "Frasa adalah unsur sintaksis yang terkecil”. Interferensi tersebut terjadi karena masuknya frasa indak tarida dari bahasa Batak Mandailing ke dalam tuturan berbahasa Indonesia yang tidak sesuai dengan kaidah dan aturan bahasa yang benar. Frasa indak tarida tersebut dalam bahasa Indonesia bermakna“tidak terlihat”.

\section{Interferensi Berupa Klausa}

Interferensi gramatikal berupa klausa terdapat 9 tuturan dari 54 tuturan secara keseluruhan. Interferensi tersebut diantaranya dijelaskan sebagai berikut.

a) "Alhamdulillah sampai di potang di hari on di lehen tuhan tu hita nikmat kesehatan, kesempatan dan kemauan sahinggo hita dapat markumpul sakaligus marsilaturahmi di dalam rangka acara keluarga nasution di kota Jambi ini”.

Artinya: Alhamdulillah Tuhan memberikan kepada kita di sore hari ini nikmat kesehatan, kesempatan dan kemauan sehingga kita dapat berkumpul sekaligus bersilaturahmi di dalam rangka acara keluarga Nasution di Kota Jambi.

Pada tuturan tersebut, terdapat jenis interferensi berupa klausa. Menurut Alwasilah (dalam Aslinda dan Syafyahya, 2007:66) "Interferensi berarti adanya saling pengaruh antar bahasa”. Selanjutnya, menurut Djajasudarma (2010:55) "Klausa adalah unsur kalimat terkecil dari wacana”. Interferensi tersebut terjadi karena masuknya klausa potang di 
hari on di lehen tuhan tu hita dari bahasa Batak Mandailing ke dalam tuturan berbahasa Indonesia yang tidak sesuai dengan kaidah dan aturan bahasa yang benar. Klausa potang di hari on di lehen tuhan tu hita tersebut dalam bahasa Indonesia bermakna"Tuhan memberikan kepada kita di sore hari ini ”. Agar tidak terjadi interferensi, tuturan tersebut dapat diperbaiki menggunakan bahasa Indonesia secara utuh menjadi "Alhamdulillah Tuhan memberikan kepada kita di sore hari ini nikmat kesehatan, kesempatan dan kemauan sehingga kita dapat berkumpul sekaligus bersilaturahmi di dalam rangka acara keluarga Nasution di Kota Jambi”.

b) "Madung idokkon tuhan tai da inang"amalan yang kekal lagi solat itu lebih baik balasannya di sisi Allah dan lebih baik menjadi harapan”.

Artinya: Allah mengatakan kak: amalan yang kekal lagi solat itu lebih baik balasannya di sisi Allah dan lebih baik menjadi harapan.

Pada tuturan tersebut,terdapat jenis interferensi berupa klausa. Menurut Alwasilah (dalam Aslinda dan Syafyahya, 2007:66) "Interferensi berarti adanya saling pengaruh antar bahasa”. Adapun Menurut Rahardi (2009:71) "Klausa adalah satuan kebahasaan yang merupakan gabungan kelompok kata yang setidaknya terdiri atas subjek dan predikat”. Interferensi tersebut terjadi karena masuknya klausa Madung idokkon tuhan tai da inang dari bahasa Batak Mandailing ke dalam tuturan berbahasa Indonesia yang tidak sesuai dengan kaidah dan aturan bahasa yang benar. Klausa Madung idokkon tuhan tai da inang dalam bahasa Indonesia bermakna "Allah mengatakan kak:”. Untuk menghindari terjadinya interferensi, penutur dari tuturan tersebut dapat menggunakan bahasa Indonesia secara utuh seperti: Allah mengatakan kak: amalan yang kekal lagi solat itu lebih baik balasannya di sisi Allah dan lebih baik menjadi harapan.

\section{Interferensi Berupa Kalimat}

Interferensi gramatikal berupa kalimat terdapat 3 tuturan dari 54 tuturan secara keseluruhan. Interferensi tersebut diantaranya dijelaskan sebagai berikut.

a) “Nadong sms na, ih ma au pas mangajar da kan jadi pas au mulak tu bagas adong panggilan”.

Artinya: Tidak ada sms, aku sedang mengajar ketika waktu pulang ke rumah ada panggilan.

Pada tuturan tersebut, terdapat jenis interferensi berupa kalimat. Menurut Kridalaksana (dalam Sudipa, dkk, 2011:1) "Interferensi adalah kesalahan bahasa berupa unsur bahasa sendiri yang dibawa ke dalam dialek lain yang dipelajari”. Selanjutnya, menurut Arifin dan Tasai (2009:16) "Kalimat adalah satuan bahasa terkecil, dalam wujud lisan atau tulisan, yang mengungkapkan pikiran yang utuh”. Interferensi tersebut terjadi karena masuknya kalimat Nadong sms na, ih ma au pas mangajar da kan jadi pas au mulak tu bagas adong panggilan dari bahasa Batak Mandailing ke dalam tuturan berbahasa Indonesia yang tidak sesuai dengan kaidah dan aturan bahasa yang benar. Kalimat Nadong sms na, ih ma au pas mangajar da kan jadi pas au mulak tu bagas adong panggilan dalam bahasa Indonesia bermakna "Tidak ada sms nya, itulah aku waktu mengajarlah kan jadi waktu aku pulang ke rumah ada panggilan”. Untuk menghindari terjadinya interferensi, penutur dari tuturan tersebut dapat menggunakan bahasa Indonesia secara utuh seperti: Tidak ada sms, aku sedang mengajar ketika waktu pulang ke rumah ada panggilan”. Hal ini terjadi akibat kemampuan penutur menggunakan dua bahasa saat berkomunikasi. 


\section{SIMPULAN}

Berdasarkan hasil penelitian dan pembahasan, maka dapat diketahui bahwa jenis interferensi bahasa Batak Mandailing dalam tuturan berbahasa Indonesia pada acara Parpunguan masyarakat Mandailing Kota Jambi terdapat 5 jenis interferensi gramatikal dari aspek, morfem, kata, frasa, klausa, dan kalimat, maka dapat penuli simpulkan: 1) Jenis interferensi gramatikal bahasa Batak Mandailing dalam tuturan berbahasa Indonesia berupa morfem pada acara Parpungan masyarakat Mandailing Kota Jambi terdapat 8 tuturan dari 54 tuturan. Interferensi pada morfem terjadi karena kekacauan pada pemakaian bentuk morfem yang tidak sesuai dengan kaidah dan aturan bahasa Indonesia. 2) Jenis interferensi gramatikal bahasa Batak Mandailing dalam tuturan berbahasa Indonesia berupa kata pada acara Parpunguan masyarakat Mandailing Kota Jambi terdapat 6 tuturan dari 54 tuturan. Interferensi berupa kata terjadi akibat kekacauan pemakaian kata yang tidak sesuai dengan kaidah dan aturan bahasa Indonesia. 3) Jenis interferensi gramatikal bahasa Batak Mandailing dalam tuturan berbahasa Indonesia berupa frasa pada acara Parpunguan masyarakat Mandailing Kota Jambi terdapat 28 tuturan dari 54 tuturan. Interferensi berupa frasa terjadi karena kekacauan pengabungan frasa yang tidak sesuai dengan kaidah dan aturan bahasa Indonesia. 4) Jenis interferensi gramatikal bahasa Batak Mandailing dalam tuturan berbahasa Indonesia berupa klausa pada acara Parpunguan masyarakat Mandailing Kota Jambi terdapat 9 tuturan dari 54 tuturan. Interferensi berupa klausa terjadi karena kekacauan pada pemakaian klausa yang tidak sesuai dengan kaidah dan aturan bahasa Indonesia. 5) Jenis interferensi gramatikal bahasa Batak Mandailing dalam tuturan berbahasa Indonesia berupa kalimat pada acara Parpunguan masyarakat Mandailing Kota Jambi terdapat 3 tuturan dari 54 tuturan.
Interferensi berupa kalimat terjadi karena kekecauan penggunana kalimat yang tidak sesuai dengan kaidah dan aturan bahasa Indonesia.

\section{DAFTAR PUSTAKA}

Arifin, E. Zenal dan S. Amran Tasai. (2009). Cermat Berbahasa Indonesia. Jakarta: Akademika Pressindo.

Aslinda dan Leni Syafyahya. (2007). Pengantar Sosiolinguitik. Bandung: PT Refika Aditama.

Budiarti, Any. (2013) Interferensi Bahasa Indonesia Ke kalam Bahasa Inggris Pada Abstrak Jurnal Ilmiah. Bahasa dan Seni. Jurnal Pasundan Bandung. Vol.3, No.1.10-17. Http://sastra.um.ac.id./wpcontent/uploads/2014/02/2AnyBudia rti.

Chaer, Abdul dan Leonie Agustina. (2010). Sosiolinguistik Perkenalan Awal. Jakarta: Rineka Cipta.

Darjowidjojo, Soenjono. (2005). Psikolinguistik. Jakarta: Unika Atma Jaya.

Djajasudarma, Fatimah. (2010). Metode Linguistik. Bandung: PT. Refika Aditama.

Lapasau, Merry dan Zaenal Arifin. (2016). Sosiolinguistik. Jakarta: PT. Pustaka Mandiri.

Muhammad. (2011). Metode Penelitian Bahasa. Yogyakarta: Ar- Ruzz Media.

Rahimah, Anni, dkk. (2015). Jurnal Bahasa, Sastra, Pembelajaran. Journal UNP, Vol.3. 96-105. Http: //ejournal.unp.ac.id/index.php/bsp/art icle/download/4916/3869.

Rofii, Afif. (2016) An Analysis of Syntactical Ability of Second Language Children Age 5-6 Years Old in Taman Kanak-Kanak (TK) Para Bintang Kota Jambi. Jurnal Ilmiah Dikdaya, Vol. 06, Nomor 1 
2016.http://dikdaya.unbari.ac.id/inde

x.php/dikdaya/article/view/38

Rokhman, Fathur. (2013). Sosiolinguistik.

Yogyakarta: Graha Ilmu.

Sartini. (2008). . “Interferensi Penggunaan

Tanda Tanya Bahasa Jawa

terhadap Kalimat Tanya Bahasa

Indonesia dalam Proses Belajar

Mengajar Siswa Kelas II Jurusan

Penjualan SMK Harapan Tahun

Pelajaran 2007-2008”. Skripsi.

FKIP Bahasa dan Sastra Indonesia.

Universitas Batanghari.

Siswantoro. (2010). Metode Penelitian

Sastra. Yogyakarta: Pustaka

Belajar.

Suandi, Nengah. (2014). Sosiolinguistik. Yogyakarta: Graha Ilmu.

Sudipa, Nengah, dkk. (2011). Interferensi.

Bali: Udayana University Press.

Suhardi. (2013). Pengantar Linguistik

Umum. Yogyakarta: Ar-Ruzz

Media.

Sukoyo, Joko. (2011). Lingua Jurnal

Bahasa dan Sastra. Portal Garuda.

Vol. VII, 95-102.

(http://download.portalgaruda.org/j

ounal.php?jounal) 